\title{
Acetone Measurement
}

National Cancer Institute

\section{Source}

National Cancer Institute. Acetone Measurement. NCI Thesaurus. Code C147288.

The determination of the amount of acetone present in a sample. 